\title{
Penerapan Metode Profile Matching pada Sistem Pendukung Keputusan Pemilihan Ketua Program Studi (STUDI Kasus: Program Studi Teknik Informatika STMIK Musi Rawas)
}

\author{
(Implementation of Profile Matching Method in Decision \\ Support System of Selection of Study Program Leader \\ (Case Study: Informatics Engineering STMIK Musi Rawas)
}

\author{
Andri Anto Tri Susilo \\ STMIK Musi Rawas, Technical Information Departement, Lubuklinggau, South Sumatera \\ Jl. Jend. Besar H.M Soeharto Km.13 Kel. Lubukkupang \\ Kecamatan Lubuklinggau Selatan I Kota Lubuklinggau 31626 \\ Telp. 085368117030 \\ andri.lubuklinggauegmail.com
}

\begin{abstract}
Abstrak - Dalam struktur organisasi suatu program studi, selalu dipimpin oleh seorang ketua program studi. Di STMIK Musi Rawas, proses pemilihan ketua program studi biasanya ditunjuk langsung oleh ketua yayasan. Kekurangan dari proses penunjukan langsung adalah tidak bisa melihat kemampuan yang dimiliki oleh calon ketua program studi baik itu kemampuan social, perencanaan, pengelolaan pembelajaran, pengelolaan Sumber Daya Manusia, Keuangan dan lain sebagainya. Sistem pendukung keputusan merupakan sistem yang dapat digunakan untuk membantu mengambil keputusan berdasarkan criteria yang ada. Dalam penelitian ini metode yang digunakan adalah metode Profile Matching. Konsep metode Profile Matching adalah membandingkan antara kompetensi individu kedalam kompetensi jabatan sehingga dapat diketahui perbedaan kompetensinya (disebut juga gap), semakin kecil gap yang dihasilkan maka bobot nilainya semakin besar yang berarti memiliki peluang lebih besar untuk seseorang menempati posisi tersebut. Hasil akhir dari penelitian ini adalah didapatkan informasi peringkat dari setiap calon ketua Program Studi dengan didasarkan pada perhitungan Profile Matching.
\end{abstract}

Abstract-- In the organizational structure of a study program, always led by a chairman of the study program. In STMIK Musi Rawas, the process of selecting the head of the study program is usually appointed directly by the chairman of the foundation. The shortcomings of the direct appointment process is not able to see the capabilities possessed by the candidate chairman of the study program be it social skills, planning, management of learning, management of Human Resources, Finance and so forth. Decision support system is a system that can be used to help make decisions based on existing criteria. In this research the method used is Profile Matching method. The concept of Profile Matching method is to compare individual competence into job competence so that it can know the difference of competence (also called gap), the smaller the gap that is generated, the greater the value the greater the greater the chance for someone to occupy the position. The final result of this research is got the rank information from each candidate of Study Program leader based on Profile Matching calculation.

Keywords: election, decision support system, Profile Matching

Kata-kata Kunci: pemilihan, system pendukung keputusan, Profile Matching. 


\section{PENDAHULUAN}

Sekolah Tinggi Manajemen dan Ilmu Komputer (STMIK) Musi Rawas, didirikan oleh Dr.H Sardiyo,MM merupakan salah satu sekolah tinggi swasta yang ada di Kota Lubuklinggau Provinsi Sumatera Selatan yang berada dibawah naungan Yayasan Pendidikan Dwi Tunggal Palembang. Pada awal berdiri, STMIK Musi Rawas hanya memiliki dua program studi yaitu Teknik Informatika dan Sistem Komputer, namun seiring berjalannya waktu, saat ini STMIK Musi Rawas memiliki tiga program studi yaitu Teknik Informatika, Sistem Komputer dan Sistem Informasi. Dalam struktur organisasi suatu program studi, selalu dipimpin oleh seorang ketua program studi. Di STMIK Musi Rawas, proses pemilihan ketua program studi biasanya ditunjuk langsung oleh ketua yayasan. Proses pemilihan dengan cara penunjukan langsung seperti ini memiliki sisi positif dan negative. Sisi positifnya adalah yayasan bisa menghemat biaya karena dengan adanya penunjukan langsung maka yayasan tidak perlu biaya untuk proses pemilihan(mulai dari pencalonan, pemaparan visi dan misi, pemungutan suara sampai ke hasil akhir) dan juga dengan penunjukan langsung bisa menghemat waktu yang dibutuhkan.

Sisi negative dari proses penunjukan langsung adalah tidak bisa melihat kemampuan yang dimiliki oleh calon ketua program studi baik itu kemampuan social, perencanaan, pengelolaan pembelajaran, pengelolaan Sumber Daya Manusia, Keuangan dan lain sebagainya yang hal ini hanya bisa diketahui melalui proses seleksi. Sehingga yang kadangkala terjadi adalah terpilihnya Ketua Program Studi yang tidak kemampuan yang dibutuhkan untuk memimpin sebuah program studi.

Berdasarkan situasi tersebut, maka diperlukan suatu system yang dapat membantu pihak yayasan untuk mempermudah dalam memilih atau menunjuk seorang Ketua Program Studi.

Sistem pendukung keputusan merupakan system yang dapat digunakan untuk membantu mengambil keputusan berdasarkan criteria yang ada. Pada hakekatnya kegiatan pembuatan keputusan dilatarbelakangi oleh adanya suatu masalah atau problem dalam usaha pencapaian suatu tujuan tertentu [1].

Ada beberapa penelitian tentang sistem pendukung keputusan yang dijadikan referensi oleh penulis, salah satunya oleh [2] yang melakukan penelitian tentang pemilihan dosen terbaik berbasis web dengan menggunakan metode Simple Additive Weighting $(S A W)$. Dalam pemilihan dosen terbaik ada beberapa criteria yang digunakan yaitu kriteria kualitas pengajaran, kedisiplinan dan penilaian teman sejawat. Penelitian lain dilakukan oleh [3] yang melakukan pengembangan sistem pendukung keputusan untuk pemilihan ketua senat mahasiswa menggunakan logika fuzzy. Dalam penelitian ini dijelaskan bahwa dalam menentukan ketua senat mahasiswa ada beberapa input yang diperlukan yaitu nilai IPK, semester, aktif kuliah dan aktif organisasi. Penelitian tentang sistem pendukung keputusan selanjutnya adalah oleh [4] yang melakukan penelitian tentang penentuan mahasiswa berprestasi di Universitas Muhammadiyah Purwokerto Menggunakan metode Weighted Product (WP). Dalam penelitian ini proses penentuan mahasiswa berprestasi ditentukan oleh beberapa kriteria yaitu indek prestasi kumulatif, karya tulis ilmiah prestasi atau kemampuan yang diunggulkan dan kemampuan bahasa inggris.

Sistem pendukung keputusan pemilihan Ketua Program Studi Teknik Informatika STMIK Musi Rawas dibangun dengan menggunakan suatu metode yaitu Metode Profile Matching. Konsep metode Profile Matching adalah membandingkan antara kompetensi individu kedalam kompetensi jabatan sehingga dapat diketahui perbedaan kompetensinya (disebut juga gap), semakin kecil gap yang dihasilkan maka bobot nilainya semakin besar yang berarti memiliki peluang lebih besar untuk seseorang menempati posisi tersebut.

Tujuan dari penelitian ini yaitu membangun suatu sistem pendukung keputusan dengan menggunakan metode Profile Matching untuk membantu proses pemilihan Ketua Program Studi Teknik Informatika dengan melihat nilai tertinggi hasil perengkingan berdasarkan beberapa aspek penilaian diantaranya kepribadian, social, perencanaan, pengelolan pembelajaran, pengelolaan sumber daya manusia, pengelolaan sarana dan prasarana, pengelolaan keuangan dan evaluasi dan pelaporan.

\section{METODE PENELITIAN}

Jenis penelitian ini adalah penelitian pengembangan yaitu pengembangan system pendukung keputusan dengan metode Profile Matching pada proses pemilihan ketua program studi Teknik Informatika STMIK Musi Rawas. 
Data penelitian ini dikumpulkan melalui metode Kuisioner. Kuisioner dilakukan kepada 10 dosen tetap dari 18 dosen tetap yang ada pada program studi Teknik Informatika. Hasil dari kuisioner adalah mendapatkan informasi tentang bobot nilai dari aspek penilaian yang telah ditentukan.

Pada tahap perancangan system dilakukan berdasarkan hasil analisis data yang ada. Perancangan system yang dibuat digambarkan dalam bentuk flowchart. Flowchart Sistem Pendukung Keputusan Pemilihan Ketua Program Studi Teknik Informatika dapat dilihat seperti Gambar 1.

Flowchart system pendukung keputusan pemilihan ketua Prodi Teknik Informatika menjelaskan alur proses pemilihan ketua Program Studi Teknik Informatika STMIK Musi Rawas. Aspek penilaian yang digunakan adalah 8 aspek penilaian dengan beberapa kriteria yang ada di setiap aspek [5]. Adapun 8 Aspek Penilaian dan kriteria tiap aspek dapat dilihat pada TABEL I.

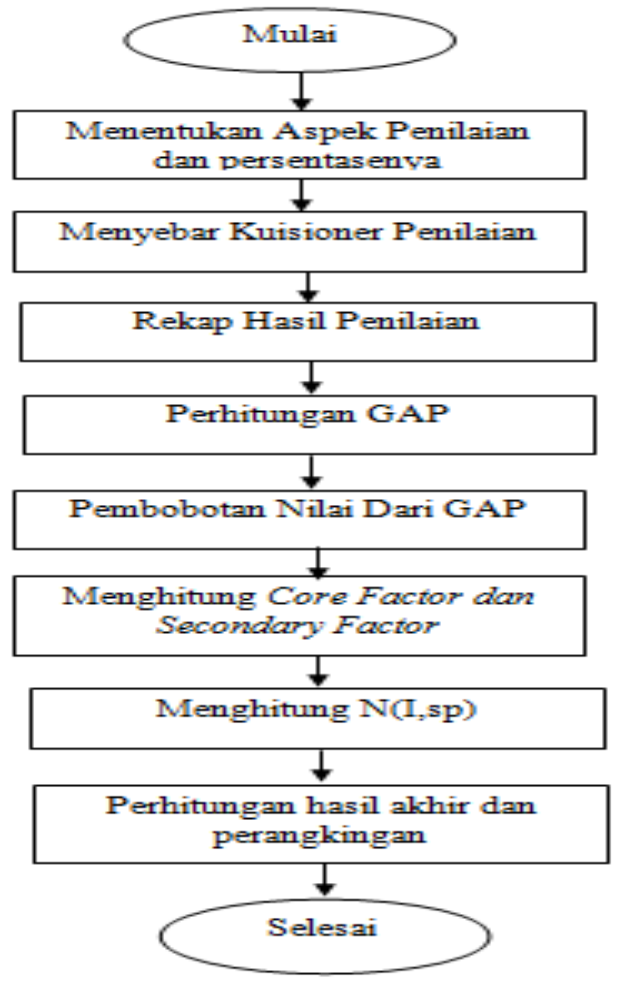

Gambar 1. Flowchart Sistem Pendukung Keputusan Pemilihan Ketua Program Studi Teknik Informatika

TABEL I

ASPEK PENILAIAN

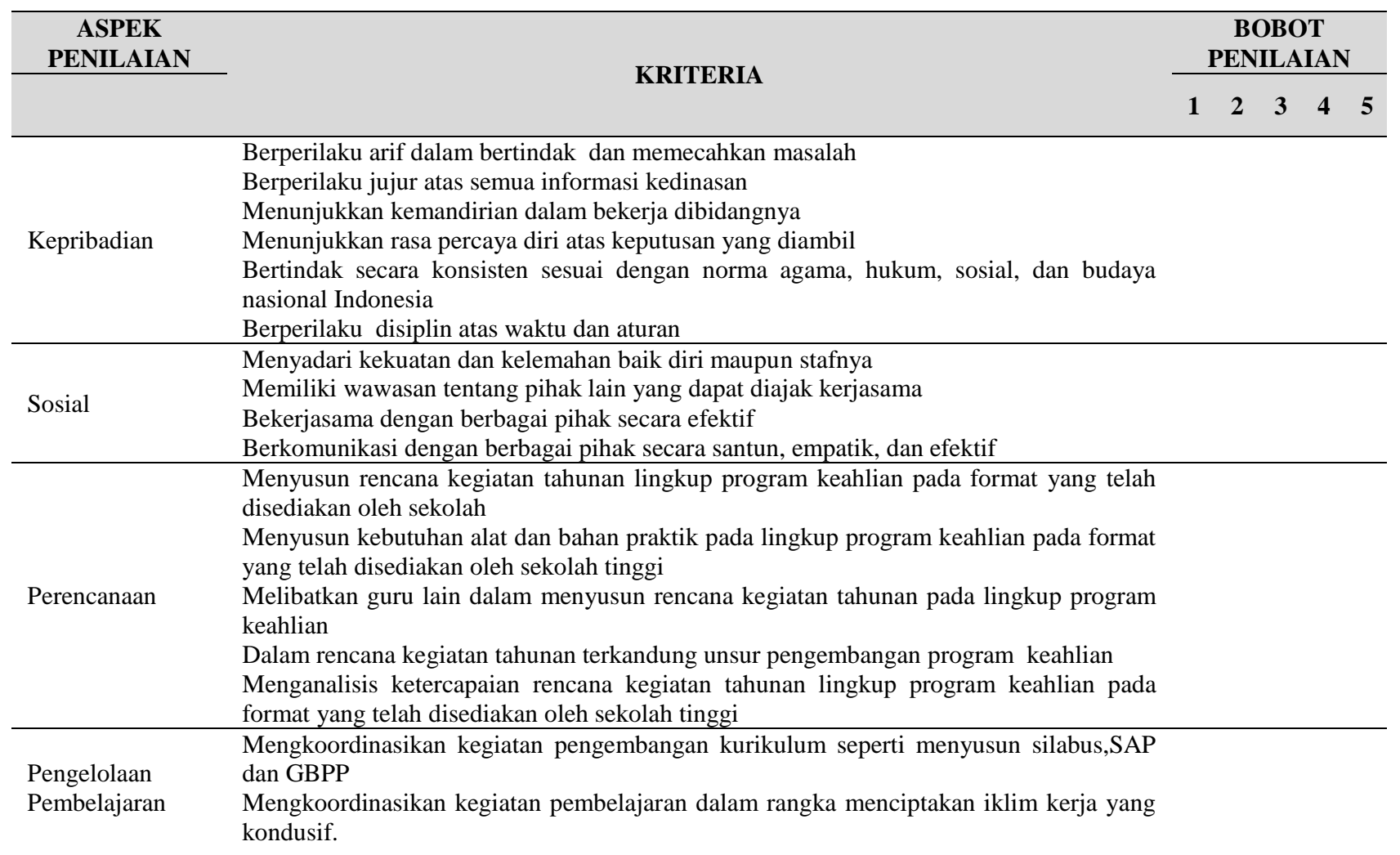




\section{TABEL I (LANJUTAN)}

\begin{tabular}{|c|c|}
\hline & Menyediakan media presentasi dengan menggunakan komputer dan digital projector \\
\hline & $\begin{array}{l}\text { Memotivasi mahasiswa dalam pembelajaran dan pengembangan kapasitas peserta didik. } \\
\text { Mengkoordinasikan kegiatan peserta didik dalam pembelajaran dan pengembangan } \\
\text { kapasitas mahasiswa }\end{array}$ \\
\hline $\begin{array}{l}\text { Pengelolaan } \\
\text { Sumber Daya } \\
\text { Manusia }\end{array}$ & $\begin{array}{l}\text { Menyusun jadwal mengajar guru pada lingkup program keahlian } \\
\text { Melakukan pembagian tugas kepala bengkel/sanggar/ laboratorium dan atau } \\
\text { teknisi/laboran pada lingkup program keahlian } \\
\text { Memberikan motivasi positif kepada guru, kepala bengkel/ sanggar/ laboratorium dan } \\
\text { teknisi/laboran dalam melaksanakan tugasnya. } \\
\text { Melakukan koordinasi kegiatan guru, kepala bengkel/ sanggar/ laboratorium dan teknisi/ } \\
\text { laboran dalam melaksanakan tugasnya. }\end{array}$ \\
\hline $\begin{array}{l}\text { Pengelolaan } \\
\text { Sarana dan } \\
\text { Prasarana }\end{array}$ & $\begin{array}{l}\text { Menyusun jadwal penggunaan bengkel/sanggar/ laboratorium pada lingkup program } \\
\text { keahlian } \\
\text { Memiliki perangkat adminsitrasi pengelolaan sarana dan prasarana } \\
\text { bengkel/sanggar/laboratorium dalam rangka tertib administrasi sarana dan prasarana. } \\
\text { Mengkoordinasikan pemeliharaan kondisi sarana dan prasarana bengkel/ sanggar/ } \\
\text { laboratorium dengan kepala bengkel/ sanggar/laboratorium dan atau teknisi/laboran } \\
\text { Mengkoordinasikan kebersihan ruangan, gedung dan halaman dengan petugas } \\
\text { kebersihan }\end{array}$ \\
\hline $\begin{array}{l}\text { Pengelolaan } \\
\text { Keuangan }\end{array}$ & $\begin{array}{l}\text { Memiliki rencana anggaran dan belanja program keahlian } \\
\text { Memiliki perangkat administrasi keuangan lingkup program keahlian. } \\
\text { Menggunakan dana secara efektif dan efisien untuk kegiatan dan kemajuan program } \\
\text { keahlian yang diampunya. } \\
\text { Mendelegasikan pengelolaan keuangan kepada bendahara }\end{array}$ \\
\hline $\begin{array}{l}\text { Evaluasi dan } \\
\text { Pelaporan }\end{array}$ & $\begin{array}{l}\text { Memantau pelaksanaan kegiatan pembelajaran pada lingkup programi keahlian } \\
\text { Memantau ketersediaan dan kondisi alat dan bahan praktikum } \\
\text { Menyusun laporan keuangan pada lingkup program keahlian } \\
\text { Menyusun laporan kegiatan tahunan pada lingkup program keahlian }\end{array}$ \\
\hline
\end{tabular}

\section{HASIL DAN PEMBAHASAN}

Berdasarkan hasil kuisioner yang diberikan maka didapat hasil kuisioner yang dipaparkan dalam bentuk tabel. Rekap hasil penilaian dapat dilihat pada TABEL II. Setelah merekap hasil kuisioner dari 8 aspek yang ada maka selanjutnya adalah menghitung GAP . Perhitungan nilai GAP dilihat dari selisih antara nilai tiap aspek dengan nilai profil jabatan yang diberikan. Proses perhitungan Nilai GAP dapat dilihat pada TABEL III.

TABEL II REKAP HASIL KUISIONER

\begin{tabular}{|c|c|c|c|c|c|c|c|}
\hline No & ID_Narasumber & 1 & 2 & 3 & 4 & 5 & 6 \\
\hline 1 & N001 & 4 & 4 & 4 & 4 & 4 & 4 \\
\hline 2 & N002 & 3 & 3 & 4 & 4 & 3 & 3 \\
\hline 3 & N003 & 4 & 4 & 3 & 3 & 2 & 3 \\
\hline 4 & N004 & 4 & 5 & 5 & 4 & 3 & 3 \\
\hline 5 & N005 & 3 & 3 & 3 & 4 & 4 & 3 \\
\hline 6 & N006 & 2 & 3 & 3 & 3 & 4 & 4 \\
\hline 7 & N007 & 3 & 4 & 3 & 3 & 2 & 3 \\
\hline 8 & N008 & 4 & 4 & 5 & 4 & 3 & 3 \\
\hline 9 & N009 & 3 & 3 & 4 & 4 & 4 & 3 \\
\hline 10 & N010 & 2 & 4 & 4 & 3 & 4 & 4 \\
\hline
\end{tabular}

TABEL III

PERHITUNGAN NILAI GAP

\begin{tabular}{|c|c|c|c|c|c|c|c|c|}
\hline No & Id_CAKA & 1 & 2 & 3 & 4 & 5 & 6 & \\
\hline 1 & Caka_01 & 3 & 4 & 4 & 4 & 3 & 3 & \\
\hline 2 & Caka_02 & 3 & 3 & 3 & 3 & 4 & 3 & \\
\hline 3 & Caka_03 & 4 & 4 & 4 & 4 & 3 & 3 & \\
\hline $\begin{array}{c}\text { Profil } \\
\text { Jabatan }\end{array}$ & & 4 & 4 & 3 & 4 & 4 & 5 & \\
\hline 1 & Caka_01 & -1 & 0 & 1 & 0 & -1 & -2 & \\
\hline 2 & Caka_02 & -1 & -1 & 0 & -1 & 0 & -2 & GAP \\
\hline 3 & Caka_03 & 0 & 0 & 1 & 0 & -1 & -2 & \\
\end{tabular}

Setelah proses perhitungan nilai GAP, selanjutnya adalah menghitung bobot nilai tiap aspek, penghitungan bobot nilai didasarkan pada ketentuan yang ada. Penghitungan bobot nilai dapat dilihat pada TABEL IV berikut.

TABEL IV

\section{PENGHITUNGAN BOBOT NILAI}

\begin{tabular}{|c|c|c|c|c|c|c|c|}
\hline No & Id_CAKA & 1 & 2 & 3 & 4 & 5 & 6 \\
\hline 1 & Caka_01 & 3 & 4 & 4 & 4 & 3 & 3 \\
\hline 2 & Caka_02 & 3 & 3 & 3 & 3 & 4 & 3 \\
\hline 3 & Caka_03 & 4 & 4 & 4 & 4 & 3 & 3 \\
\hline \multicolumn{2}{|c|}{ Profil } & 4 & 4 & 3 & 4 & 4 & 5 \\
\hline 1 & Caka_01 & -1 & 0 & 1 & 0 & -1 & -2 \\
\hline \multicolumn{2}{|c|}{ Pombobotan } & 4 & 5 & 4.5 & 5 & 4 & 3 \\
\hline 2 & Caka_02 & -1 & -1 & 0 & -1 & 0 & -2 \\
\hline \multicolumn{2}{|c|}{ Pembobotan } & 4 & 4 & 5 & 4 & 5 & 3 \\
\hline 3 & Caka_03 & 0 & 0 & 1 & 0 & -1 & -2 \\
\hline \multicolumn{2}{|c|}{ Pembobotan } & 5 & 5 & 4.5 & 5 & 4 & 3 \\
\hline
\end{tabular}


Setelah menentukan bobot nilai gap untuk tiap aspek yang ada dalam 8 kriteria, maka langkah berikutnya adalah mengelompokkan tiap kriteria dalam 8 aspek menjadi 2 kelompok "Core Factor" dan "Secondary Factor". Setelah memisahkan kedalam 2 kelompok, selanjutnya adalah menghitung core factor dengan persamaan 1 .

$$
\mathbf{N C F}=\frac{\sum \mathrm{NC}(\mathrm{i}, \mathrm{s}, \mathrm{p})}{\sum \mathrm{IC}}
$$

Keterangan :

$$
\begin{array}{ll}
\mathrm{NCF} & \text { : Nilai rata-rata core factor } \\
\mathrm{NC}(\mathrm{i}, \mathrm{s}, \mathrm{p}) & \text { : Jumlah total nilai core factor } \\
\mathrm{IC} & \text { : Jumlah item core factor }
\end{array}
$$

Dan menghitung secondary factor dengan persamaan 2 .

$$
\mathbf{N S F}=\frac{\sum \mathrm{NS}(\mathrm{i}, \mathrm{s}, \mathrm{p})}{\sum \mathrm{IS}}
$$

Keterangan :

$$
\begin{array}{ll}
\text { NSF } & \text { : Nilai rata-rata secondary factor } \\
\text { NS (i,s,p) } & \text { : Jumlah nilai total secondary factor } \\
\text { IS } & \text { : Jumlah item secondary factor }
\end{array}
$$

Hasil perhitungan core factor dapat dilihat seperti TABEL V berikut.
TABEL V

HASIL PERHITUNGAN CORE FACTOR

\begin{tabular}{|l|c|c|c|c|c|c|c|r|}
\hline $\begin{array}{l}\text { Profil } \\
\text { Jabatan }\end{array}$ & 5 & 5 & 3 & 3 & 4 & Core Factor & Secondary Factor \\
\hline 1 & Caka_01 & -1 & -1 & 1 & 1 & 0 & & 4.5 \\
\hline Pembobotan & 4 & 4 & 4.5 & 4.5 & 5 & 4.333333333 & 4.75 \\
\hline 2 & Caka_02 & -1 & -1 & 1 & 0 & 0 & & 4 \\
\hline Pembobotan & 4 & 4 & 4.5 & 5 & 5 & 4.333333333 & 4.75 \\
\hline 3 & & & & & & & 4 \\
\hline
\end{tabular}

Dari perhitungan setiap kriteria dari 8 aspek yang diatas, berikutnya dihitung nilai total berdasarkan presentase dari core factor dan secondary factor yang diperkirakan berpengaruh terhadap pemilihan ketua program studi. Penghitungan nilai total menggunakan persamaan 3 .

$$
(x) \% . N C F(i . s . p)+(x) \% . N S F(i . s . p)=N(i . s . p)
$$

Keterangan:

$\mathrm{NCF}$ : Nilai rata-rata core factor

NSF : Nilai rata-rata secondary factor

$\mathrm{N} \quad$ : Nilai total dari aspek

$(\mathrm{x}) \% \quad$ : Nilai persen yang diinputkan

Hasil perhitungan nilai total dapat dilihat pada TABEL VI berikut.

TABEL VI

PERHITUNGAN NILAI TOTAL

\begin{tabular}{|c|c|c|c|c|c|c|c|c|c|c|}
\hline \multicolumn{2}{|c|}{ Profil } & 4 & 4 & 3 & 4 & 4 & 5 & Core Factor & Secondary Factor \\
\hline 1 & Caka_01 & -1 & 0 & 1 & 0 & -1 & -2 & & NK \\
\hline Pembobotan & 4 & 5 & 4.5 & 5 & 4 & 3 & 4.333333333 & 4.1666666667 & 4.266666667 \\
\hline & & & & & & & & \\
\hline \\
\hline
\end{tabular}

Hasil akhir dari proses profile matching adalah ranking dari kandidat yang diajukan untuk mengisi suatu jabatan tertentu. Penentuan ranking mengacu pada hasil perhitungan dengan persamaan 4 .

\section{$\underline{\text { Ranking }=(\mathrm{x}) \% . \mathrm{NK}+(\mathrm{x}) \% . \mathrm{Ns}+(\mathrm{x}) \% \cdot \mathrm{Np}+(\mathrm{x}) \% . \mathrm{NPP}+(\mathrm{x}) \% \cdot \mathrm{NPSDM}+(\mathrm{x}) \% . \mathrm{Npsp}+(\mathrm{x}) \% . \mathrm{NPK}+(\mathrm{x}) \% . \mathrm{NEP}}$}

Keterangan:

$\begin{array}{ll}\text { Nk } & \text { : Nilai Kepribadian } \\ \text { Ns } & \text { : Nilai Sosial } \\ \text { Np } & \text { : Nilai Perencanaan } \\ \text { NPP } & \text { : Nilai Pengelolaan Pembelajaran }\end{array}$

NPSDM: Nilai Pengelolaan SDM

NPSP : Nilai Pengelolaan Sarana dan Prasarana 


$\begin{array}{ll}\text { NPK } & \text { : Nilai Pengelolaan Keuangan } \\ \text { NEP } & \text { : Nilai Evaluasi dan Pelaporan } \\ (\mathbf{x}) \% & \text { :Nilai Persen yang diinputkan }\end{array}$

Hasil perhitungan akhir dapat dilihat pada TABEL VII berikut.

TABEL VII

PERHITUNGAN AKHIR PROFILE MATCHING

Nilai Awal
\begin{tabular}{|c|c|c|c|c|c|c|c|c|c|}
\hline No & ID_CAKA & NK & NS & NP & NPP & NPSDM & NPSP & NPK & NEP \\
\hline 1 & Caka_01 & 4.266666667 & 4.1 & 4.7 & 4.4 & 4.65 & 4.6 & 4.2 & 4.1 \\
\hline 2 & Caka_02 & 4.2 & 4.35 & 4.2 & 4.5 & 4.9 & 4.6 & 4.2 & 4.8 \\
\hline 3 & Caka_03 & 4.466666667 & 4.5 & 4.4 & 4.3 & 5 & 5 & 4.2 & 4.5 \\
\hline
\end{tabular}

\begin{tabular}{|c|c|c|c|c|c|c|c|c|c|c|c|}
\hline 2 & Caka_O2 & 0.336 & 0.3045 & 0.63 & 1.125 & 0.49 & 0.46 & 0.63 & 0.48 & 4.4555 & 2 \\
\hline
\end{tabular}

Pada sistem pendukung keputusan pemilihan ketua Program Studi Teknik Informatika proses perhitungan dilakukan dengan cara memasukkan komponen penilaian yang telah di rekap Proses input nilai Aspek dapat dilihat seperti pada Gambar 2.

\begin{tabular}{|c|c|c|c|c|c|c|}
\hline \multicolumn{3}{|c|}{ I : :.: Sistem Pendukung Keputusan Pemilihan Ketua Prodi } & & & \multicolumn{2}{|c|}{\begin{tabular}{|l|l|l|}
$口$ & 0 & -1 \\
\end{tabular}} \\
\hline \multicolumn{7}{|c|}{ - Data DiriCalon- } \\
\hline \multirow{4}{*}{$\begin{array}{l}\text { ID Caka } \\
\text { NIDN } \\
\text { Nama Caka } \\
\text { Jabatan }\end{array}$} & \multicolumn{5}{|c|}{ Cari ID Caka } & \\
\hline & \multicolumn{6}{|l|}{0228091988} \\
\hline & \multicolumn{6}{|l|}{ Rusdifanto,MLom } \\
\hline & \multicolumn{6}{|l|}{ Dosen Tetap } \\
\hline \multicolumn{7}{|c|}{ Penialain Aspek } \\
\hline \multicolumn{3}{|c|}{ - A Aspek Kepribadian } & \multirow{2}{*}{$\begin{array}{l}\text { D. Aspek Pengelolaan Pengajaran } \\
\text { 1. Mcnya darikckuatan dan kcl cmahanbailk diri maupun } \\
\text { stafnya }\end{array}$} & & \multirow{2}{*}{$\begin{array}{l}\text {-G. Aspek Pengeloadn Keuangan - } \\
\text { 1. Mcnya darikckuatan dan kclemahanbail diri maupun } \\
\text { stafnya }\end{array}$} & \\
\hline $\begin{array}{l}\text { 1. Berpenita } \\
\text { masalah }\end{array}$ & a arf dalambertindak danmemecahkan & 3 & & 4 & & 3 \\
\hline \multicolumn{2}{|c|}{ 2. Kempenlakily } & 4 & \multirow{3}{*}{$\begin{array}{l}\text { 2. Memulka wawa santent angpinak lamyang dapat diajak } \\
\text { ketjasallid } \\
\text { 3 Rekerjasama denganherha gai pihak secara efektif }\end{array}$} & 4 & \multirow{3}{*}{ 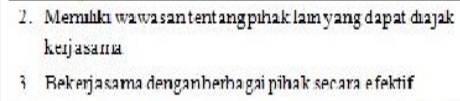 } & 3 \\
\hline 3. Menunj & kankemandirian dalam bekerja dibidangnya & 4 & & 4 & & 3 \\
\hline \multirow{2}{*}{\multicolumn{2}{|c|}{$\begin{array}{l}\text { 4. Menumjukkanrasa percaya diri at as keputusan y ang } \\
\text { diambil }\end{array}$}} & $44_{4}$ & & & & \\
\hline & & $14^{4}$ & \multirow{2}{*}{$\begin{array}{l}\text { 1. Berkomunika ci dengan berb agai pihak secara eantum, } \\
\text { empatik, dan efektif } \\
. .\end{array}$} & 4 & $\begin{array}{l}\text { 1. Berkomunikaci dengan berb agai pihak eecara eantum, } \\
\text { empatik, dan efektif }\end{array}$ & 3 \\
\hline \multicolumn{2}{|c|}{$\begin{array}{l}\text { 5. Deitindak sec ara konsisten sesuai dengan noma agama, } \\
\text { hukum, sosial, dan budaya nasional Indonesia }\end{array}$} & 3 & & & . . & \\
\hline 6. Berperils & 1) displin ata 3 waltu dan aturan & 3 & $\begin{array}{l}\text { E. Aspek Pengeloadn SDM } \\
\text { 1. Mcnya darikckuatan dan kclcmahanbail diri maupun } \\
\text { stafnya }\end{array}$ & 4 & $\begin{array}{l}\text { H. Aspek Evaluasi dan Pelaporan - } \\
\text { 1. Mcnya darikckuatan dan kclcmahanbail diri maupun } \\
\text { stafnya }\end{array}$ & 3 \\
\hline \multicolumn{3}{|l|}{ B. Aspek Sosial- } & 2. Memulka wa wa santent angphak lamyang dapat dajak & 4 & 2. Memulka wa wa santent angpihak lamyang dapat dajak & 3 \\
\hline \multicolumn{2}{|c|}{$\begin{array}{l}\text { 1. Menya dari kckuatan dan kclemahan bailk diri maupun } \\
\text { sta fnya }\end{array}$} & 3 & $\begin{array}{l}\text { ketjasallla } \\
3 \text { Rekerjasama denganherha gai pihak secara efektif }\end{array}$ & 4 & 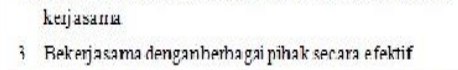 & 3 \\
\hline \multicolumn{2}{|c|}{$\begin{array}{l}\text { 2. Memuluk wa wa santent ang pihak lamyang dapat diajak } \\
\text { ketjasdill } \\
\text { 3 Rekerjasama denganherhagai pihak secara efektif }\end{array}$} & 3 & $\begin{array}{l}\text { 1. Berkomunikasi dengan berb agaipihak secara eantum, } \\
\text { empatik, dan efektif } \\
\text {.. . . . .. . . }\end{array}$ & 4 & $\begin{array}{l}\text { 1. Berkomunika i dengan berb agui pihak secara eantum, } \\
\text { empatik, dan efektif } \\
\text {.. . . . . . . }\end{array}$ & 4 \\
\hline 1. Berkom & ikasi dengan berb agai pihak secara eantum, & 13 & & & & \\
\hline
\end{tabular}

\section{Gambar 2. Proses Input Penilaian Aspek}

\section{PENUTUP}

Berdasarkan hasil penelitian yang telah dilakukan maka dapat diambil kesimpulan sebagai berikut:
1. Sistem pendukung keputusan yang dibangun dapat membantu pimpinan yayasan untuk menentukan calon Ketua Program Studi Teknik Informatika STMIK Musi Rawas 
2. Nilai calon Ketua Program Studi Teknik Informatika yang tertinggi dapat dijadikan pertimbangan dalam memilih Ketua Program Studi Teknik Informatika STMIK Musi Rawas.

\section{DAFTAR PUSTAKA}

[1] Sutabri, T., 2005, Sistem Informasi Manajemen, Andi Ofset, Yogyakarta.

[2] Puput, P., Dedi., dan Nova, R., 2015, "Sistem Pendukung Keputusan Pemilihan Dosen Terbaik Berbasis Web Dengan Metode SAW(Simple Additive Weighting) (Studi Kasus:STMIK Global Tangerang)", Jurnal Sisfotek Global, Volume 5 No 2, pp. 100-108, September 2015.
[3] Jamaludin, M., Arik, dan Sofan T., 2015, "Sistem Pendukung Keputusan Pemilihan Ketua Senat Mahasiswa Dengan Logika Fuzzy, STMIK Amikom", Seminar Nasional Teknologi Informasi dan Multimedia, hal. 235-239, Februari 2015.

[4] Mustafidah, H. dan Hadyan, H.N., 2017, "Sistem Pendukung Keputusan Penentuan Mahasiswa Berprestasi di Universitas Muhammadiyah Purwokerto Menggunakan Metode Weighted Product (WP)", JUITA, Volume 5 No 1, hal. 51-61, Mei 2017.

[5] Gultom, S., 2011, Panduan Penilaian Kinerja Ketua Program Studi, Kementerian Pendidikan Nasional Badan Pengembangan SDM Pendidikan dan Penjaminan Mutu Pendidikan, Jakarta. 